\title{
Preauricular Transzygomatic Approach for Infratemporal Fossa and Surrounding Skull Base Lesion: An Institutional Experience
}

\author{
Rajat Jain ${ }^{1}$ Amit Keshri ${ }^{1}$ Ravi Shankar Manogaran ${ }^{1}$ \\ ${ }^{1}$ Department of Neuro-Otology, Sanjay Gandhi Postgraduate \\ Institute of Medical Sciences, Lucknow, Uttar Pradesh, India \\ ${ }^{2}$ Department of Neurosurgery, Sanjay Gandhi Postgraduate Institute \\ of Medical Sciences, Lucknow, Uttar Pradesh, India
}

Raj Kumar ${ }^{2}$ Pearly Paptayil Keeranghat ${ }^{1}$

\begin{abstract}
Address for correspondence Amit Keshri, MBBS, MS, Department of Neuro-Otology, Sanjay Gandhi Postgraduate Institute of Medical Sciences, Rai Bareilly Road, Lucknow 226014, Uttar Pradesh, India (e-mail: amitkeshri2000@yahoo.com).
\end{abstract}

Ann Otol Neurotol ISO 2018;1:94-99

\begin{abstract}
Keywords

- infratemporal fossa

- preauricular transzygomatic

- pterional craniotomy

Background Preauricular transzygomatic surgical approach (PTZA) can be used to approach and resect tumors of infratemporal fossa (ITF) and surrounding skull base lesion. Various modifications in this approach can be used to approach various critical areas such as cavernous sinus, sphenoid sinus.

Materials and Methods Clinical charts were reviewed to determine the association among pathological variables, surgical procedures, and outcomes.

Results Three out of seven were malignant tumors and required pterional craniotomy and postoperative radiotherapy. 4 out of 7 were benign tumors and required craniofacial osteotomies.

Conclusion PTZA is a versatile approach for tumor of ITF with or without intracranial extradural extension and cosmetically better than other approaches. This approach is better suited for lateral ITF tumors that are difficult to access through endoscopic approaches.
\end{abstract}

\section{Introduction}

The preauricular transzygomatic surgical approach (PTZA) for infratemporal fossa (ITF) can be used to achieve a complete resection of a variety of tumors arising from or extending into the ITF. This approach can be tailored to the individual tumor and its extensions. This approach is designed for ITF lesions with or without extension to pterygopalatine fossa (PPF), sphenoid sinus, and minimal extension into cavernous sinus. Two types of preauricular approach for ITF are preauricular transzygomatic ITF approach and preauricular frontotemporal orbitozygomatic approach.

The earliest publications addressing surgical approaches to the ITF appeared in the 19th century and focused on the treatment of sphenopalatine neuralgia. These approaches were associated with high morbidity rates and failed to gain popularity. ${ }^{1}$ Till the 1960 s, the ITF was considered surgically inaccessible, and tumors that extended into the ITF had been considered inoperable. Innovative surgical approaches were introduced by Conley ${ }^{2}$ and Barbosa. ${ }^{3}$ Prof. Ugo Fisch has devised various approaches to ITF. These approaches are among the most commonly used approaches to ITF in current scenario. Various approaches are named as Fisch types A, B, and $C$. Preauricular approaches to the skull base are described by many authors including Sen and Sekhar. ${ }^{4}$ Preauricular approaches to skull base access nearly the same area as by Fisch $B$ and Fisch $\mathrm{C}$ approaches from a purely lateral vector of exposure. Skull base surgical approaches to the ITF have undergone significant changes. The most important among them is the collaboration among multidisciplinary teams involving otolaryngologists/head and neck surgeons, neurosurgeons, plastic surgeons, ophthalmologists, radiologists, and medical and radiation oncologists. Team work improves diagnosis, staging, and management of the tumor. Preauricular transzygomatic ITF approach helps in mobilization of the second and third divisions of the trigeminal nerve after drilling of the lateral loop between the foramina rotundum and ovale. Mobilization of the trigeminal nerve provides visualization of the auditory tube, tensor veli palatini muscle, and pharyngobasilar membrane. Removal of pterygoid muscles and plates allows surgical 
access to the cavernous sinus, sphenoid, nasopharynx, clivus, PPF and parapharyngeal space. ${ }^{5}$ All approaches and modifications of existing technique are to minimize injury to important neurovascular structures within and adjacent to the ITF. When selecting the surgical approach, a variety of factors such as histology, biological behavior of the tumor, the patient's characteristics, and the surgeon's experience should be considered. ${ }^{6}$ The approach described here can be modified according to the nature and extensions of a tumor. However, many do not agree with the same and advocate the use of extensive approaches regardless of the nature and extensions of the tumor. As the time has eloped now, more and more endoscopic approaches have evolved to reach ITF, but their success in large ITF tumors with lateral extension is questionable. In comparison with a lateral approach, endonasal endoscopic transpterygoid approach provides better visualization and more direct exposure of median structures such as the nasopharynx, eustachian tube, sella, and clivus. ${ }^{7}$ We studied the association among the characteristics of ITF tumors, and the variables pertaining to their surgical treatment to demonstrate the effectiveness of the PTZA according to the characteristics of individual tumors. During surgery a curvilinear incision was performed starting from in front of the tragus, coursing superiorly and then anteriorly in the frontal scalp to end superior to the supraorbital notch near the midline. This can be combined with pterional craniotomy to remove tumors with intracranial extradural extension.

\section{Materials and Methods}

Patients with tumors involving the ITF who underwent surgical treatment via a PTZA, at our super specialty tertiary care center during the period between January 2012 and June 2014, were included in the study. Total of seven patients were included, of whom three were malignant and four were benign. Their clinical charts were retrospectively reviewed, and data were collected regarding patient demographics, radiology and histopathology, and postoperative extent of excision and associated morbidity (-Table 2). Clinical and radiological reports were analyzed to establish the origin and extensions of the tumors. Based on Conley's classification, ${ }^{8}$ tumors were classified as primary tumors, originating primarily from one of the ITF structures, or as contiguous tumors, originating from the adjacent areas and locally extending into the ITF. Tumor extensions were grouped according to anatomic sites ( - Table $\mathbf{1}$ ).

They were then graded, depending on the number of structures that the tumor involved in each direction, as minor (single structure involved) and major degrees (multiple structures involved). Pathological data were reviewed to determine the type and nature of the tumor, adequacy of the resected margin, and presence of perivascular and perineural invasion. Treatment data included previous treatment modalities, plan of treatment, and use of postoperative/preoperative radiotherapy/chemotherapy. Surgical variables included incision design, osteotomies, craniotomies, and procedures other than the preauricular approach necessary to complete excision of the tumor. Complications of treatment, recurrence, need for revision surgery, and postmanagement oncological status were also noted.
Table 1 Extension as per anatomic sites

\begin{tabular}{|l|l|}
\hline Extension & Sites \\
\hline Medial & $\begin{array}{l}\text { Pterygoid plates, PPF, orbit, sinonasal } \\
\text { tract, nasopharynx, and clivus }\end{array}$ \\
\hline Superior & $\begin{array}{l}\text { Zygoma, mandible, parotid, and } \\
\text { masseter }\end{array}$ \\
\hline Intracranial & $\begin{array}{l}\text { Greater wing of sphenoid, temporal } \\
\text { bone, carotid canal, foramen jugulare, } \\
\text { foramen ovale, maxillary nerve, and } \\
\text { mandibular nerve }\end{array}$ \\
\hline Posterior & $\begin{array}{l}\text { Gasserian ganglion, cavernous sinus, } \\
\text { dura, and brain }\end{array}$ \\
\hline
\end{tabular}

Abbreviations: ICA, internal carotid artery; IJV, internal jugular vein; PPF, pterygopalatine fossa.

In the malignant and benign groups, final outcome was taken as patients who completed at least 1 year of follow-up.

\section{Results}

\section{Malignant Group}

Three patients, including one male and two females, had malignant tumors (-Table 2, - Figs 1, 2, and 3). Their ages ranged from 10 to 30 years with a mean of 19 years. Two patients were younger than 19 and one older than 19 years. Tumors originated at the ITF in two patients (chondrosarcoma, clear cell meningioma), and one (clival chordoma) had tumor that originated at the adjacent areas and then extended into the ITF. Two patients were subjected to preoperative radiotherapy (chondrosarcoma and clear cell meningioma). Near-total excision was done in clival chordoma as it was extending into cavernous sinus. Surgery was followed by radiotherapy for this patient. Surgical extirpation involved ITF dissection with pterional craniotomy. Ultimately, all patients received multimodality treatment, either during their initial treatment or as adjunctive treatment after the surgery. Reconstruction was not needed in any of the cases. No major surgical complications were encountered in any patient. Minor cosmetic disfigurement, hematoma, and infection were seen, which resolved by giving conservative management. Distant metastases developed in none. Recurrence or persistence of tumor at the local area occurred in none.

\section{Benign Group}

Four patients (three males, one female) had benign tumors (-Table 2, -Fig 4). Their ages ranged from 3 to 70 years. Mean age was 37 years. Two patients in this group were older than 37 years and two were younger than 37 years. Tumors originated in the ITF in three out of four patients; and in one out of four patients, tumors originated in the orbit and extended to the ITF. In all patients, tumors had local extensions into an adjacent area (-Table 2). Margins of resection were microscopically positive in none.

Surgery was the primary treatment for all. No patient was treated for recurrences that developed after primary surgery. Two patients underwent ITF dissection alone. ITF dissection was combined with other procedures in two (50\%) patients; 
Table 2 Patients' profile with summary of observation and management

\begin{tabular}{|c|c|c|c|c|c|c|c|c|c|}
\hline Case & $\begin{array}{l}\text { Age } \\
\text { (y) }\end{array}$ & $\mathrm{M} / \mathrm{F}$ & Symptom & $\begin{array}{l}\text { Extension } \\
\text { on imaging }\end{array}$ & Surgical approach & Craniotomy & HPE & $\begin{array}{l}\text { Malignant/ } \\
\text { benign }\end{array}$ & $\begin{array}{l}\text { Radiotherapy/ } \\
\text { chemotherapy }\end{array}$ \\
\hline 1 & 70 & $M$ & $\begin{array}{l}\text { Swelling on } \\
\text { right cheek }\end{array}$ & $\begin{array}{l}\text { Medial, } \\
\text { lateral, } \\
\text { superior, } \\
\text { posterior }\end{array}$ & \begin{tabular}{|l|} 
Preauricular \\
transzygomatic \\
approach with \\
control over carotid
\end{tabular} & No & $\begin{array}{l}\text { Maxillary artery } \\
\text { AVM }\end{array}$ & Benign & No \\
\hline 2 & 18 & $\mathrm{~F}$ & $\begin{array}{l}\text { Pain over } \\
\text { face }\end{array}$ & \begin{tabular}{|l} 
Medial, \\
lateral, \\
superior, \\
intracranial
\end{tabular} & $\begin{array}{l}\text { Preauricular } \\
\text { transzygomatic } \\
\text { approach with } \\
\text { pterional } \\
\text { craniotomy }\end{array}$ & Yes & Clival chordoma & Malignant & $\begin{array}{l}\text { Postoperative } \\
\text { radiotherapy }\end{array}$ \\
\hline 3 & 28 & $\mathrm{~F}$ & $\begin{array}{l}\text { Progressive } \\
\text { loss of vision } \\
\text { of right side }\end{array}$ & $\begin{array}{l}\text { Medial, } \\
\text { lateral, } \\
\text { superior, } \\
\text { intracranial }\end{array}$ & $\begin{array}{l}\text { Preauricular } \\
\text { frontotemporal } \\
\text { orbitozygomatic } \\
\text { approach with } \\
\text { pterional } \\
\text { craniotomy }\end{array}$ & Yes & Chondrosarcoma & Malignant & $\begin{array}{l}\text { Preoperative } \\
\text { radiotherapy }\end{array}$ \\
\hline 4 & 11 & $M$ & $\begin{array}{l}\text { Proptosis } \\
\text { with loss of } \\
\text { vision on } \\
\text { right side }\end{array}$ & $\begin{array}{l}\text { Medial, } \\
\text { lateral, } \\
\text { superior, } \\
\text { intracranial, } \\
\text { posterior }\end{array}$ & $\begin{array}{l}\text { Preauricular } \\
\text { frontotemporal } \\
\text { orbitozygomatic } \\
\text { approach with } \\
\text { Pterional } \\
\text { craniotomy }\end{array}$ & Yes & $\begin{array}{l}\text { Clear cell } \\
\text { meningioma }\end{array}$ & Malignant & $\begin{array}{l}\text { Preoperative } \\
\text { radiotherapy }\end{array}$ \\
\hline 5 & 55 & $\mathrm{~F}$ & $\begin{array}{l}\text { Swelling on } \\
\text { left forehead } \\
\text { with } \\
\text { progressive } \\
\text { loss of vision }\end{array}$ & $\begin{array}{l}\text { Medial, } \\
\text { lateral, } \\
\text { superior, } \\
\text { posterior }\end{array}$ & $\begin{array}{l}\text { Preauricular } \\
\text { transzygomatic } \\
\text { approach with } \\
\text { control over carotid }\end{array}$ & No & $\begin{array}{l}\text { Pleomorphic } \\
\text { adenoma of } \\
\text { minor salivary } \\
\text { glands }\end{array}$ & Benign & No \\
\hline 6 & 20 & $M$ & $\begin{array}{l}\text { Right cheek } \\
\text { swelling }\end{array}$ & $\begin{array}{l}\text { Medial, } \\
\text { lateral, } \\
\text { superior, } \\
\text { posterior }\end{array}$ & $\begin{array}{l}\text { Preauricular } \\
\text { transzygomatic } \\
\text { approach }\end{array}$ & No & Angiofibroma & Benign & No \\
\hline 7 & 3 & $M$ & \begin{tabular}{|l|} 
Progressive \\
loss of vision \\
right side
\end{tabular} & $\begin{array}{l}\text { Medial, } \\
\text { lateral, } \\
\text { superior, } \\
\text { posterior }\end{array}$ & $\begin{array}{l}\text { Preauricular } \\
\text { transzygomatic } \\
\text { approach }\end{array}$ & No & $\begin{array}{l}\text { Intraorbital } \\
\text { extraconal } \\
\text { orbital } \\
\text { schwannoma }\end{array}$ & Benign & No \\
\hline
\end{tabular}

Abbreviations: AVM, arteriovenous malformation; F, female; HPE, histopathology examination; M, male.

that is, in maxillary artery arteriovenous malformation (AVM), control over the common carotid artery was taken in the neck with modification in incision over the neck. In intraorbital extraconal orbital schwannoma, orbitozygomatic craniotomy was done. Reconstruction was needed in none. No major surgical complications were encountered in any of the patients. Minor complications occurred in patients which resolved by giving conservative management.

\section{Discussion}

ITF lies below middle cranial fossa (MCF), between ramus of the mandible and lateral wall of the pharynx. Roof is the skull base that is formed by greater wing of the sphenoid bone and squamous part of the temporal bone. Anteriorly, it is bounded by the maxilla, IOF, and pterygomaxillary fissure. Posteriorly, it is bounded by carotid sheath and styloid apparatus, medially by the pterygoids, and laterally by the mandible. ITF includes the anatomic area below the MCF base, and contains maxillary artery and vein, V2, V3, fat, and muscles. The ITF is difficult for clinical examination; therefore, tumors involving this region are difficult to diagnose, and they pose therapeutic challenges. Some tumors present with insidious and nonspecific signs and symptoms and are often diagnosed at later stages. A thorough history, physical examination, high degree of suspicion, and radiological assessment are essential for an early diagnosis. ${ }^{1}$ Previously, ITF tumors were considered inoperable. Advances in microsurgery and skull base surgery lead to multiple surgical approaches to the ITF, aiming for oncologically safe resections while minimizing the morbidity. Lateral skull base approaches were mainly made to minimize brain retraction. They include bone removal for exposure and for identification and preservation of vital neurovascular structures. ${ }^{10}$ The preauricular transzygomatic approach to the ITF was developed and modified with these concepts in mind. ${ }^{11,12}$

Various approaches for ITF have been designed, the most used among them are the Fisch approaches.

Unlike other Fisch approaches, PTZA allows access to ITF, without involving pinna, middle ear, and mastoid and facial nerve dissection. Incision design can be altered as per requirement for neck dissection, if needed. PTZA is suitable 

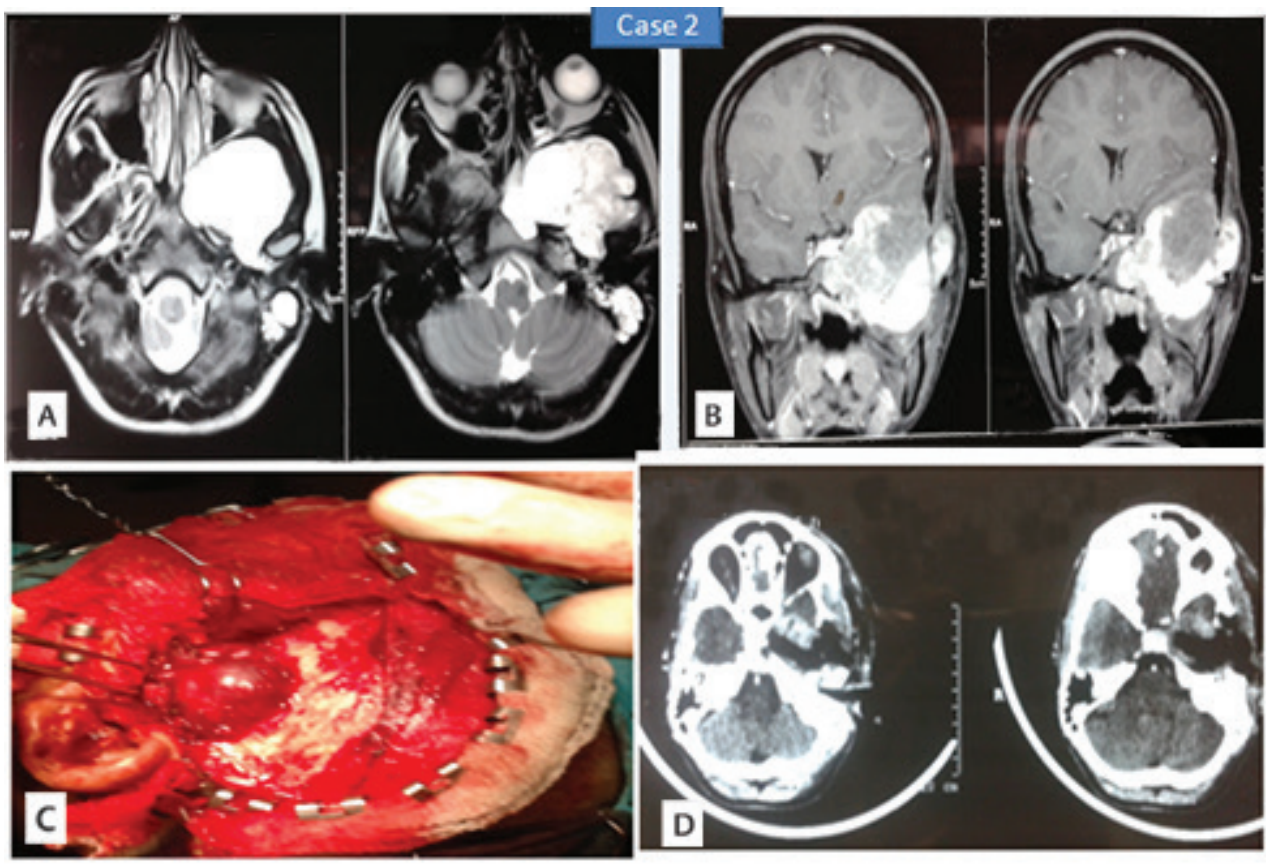

Fig. 1 Case 2. (A) Preoperative axial section of T2 MRI showing clival cordoma having intracranial extradural extension involving ITF, (B) Preoperative coronal section of T2 MRI showing clival cordoma having intracranial extradural extension involving ITF, (C) Intraoperative image showing flap with pteryional craniotomy with erosion of zygomatic root and tumor in ITF, (D) Postoperative CT scan showing complete removal of tumor from ITF and cranium. CT, computed tomography; ITF, infratemporal fossa; MRI, magnetic resonance imaging.

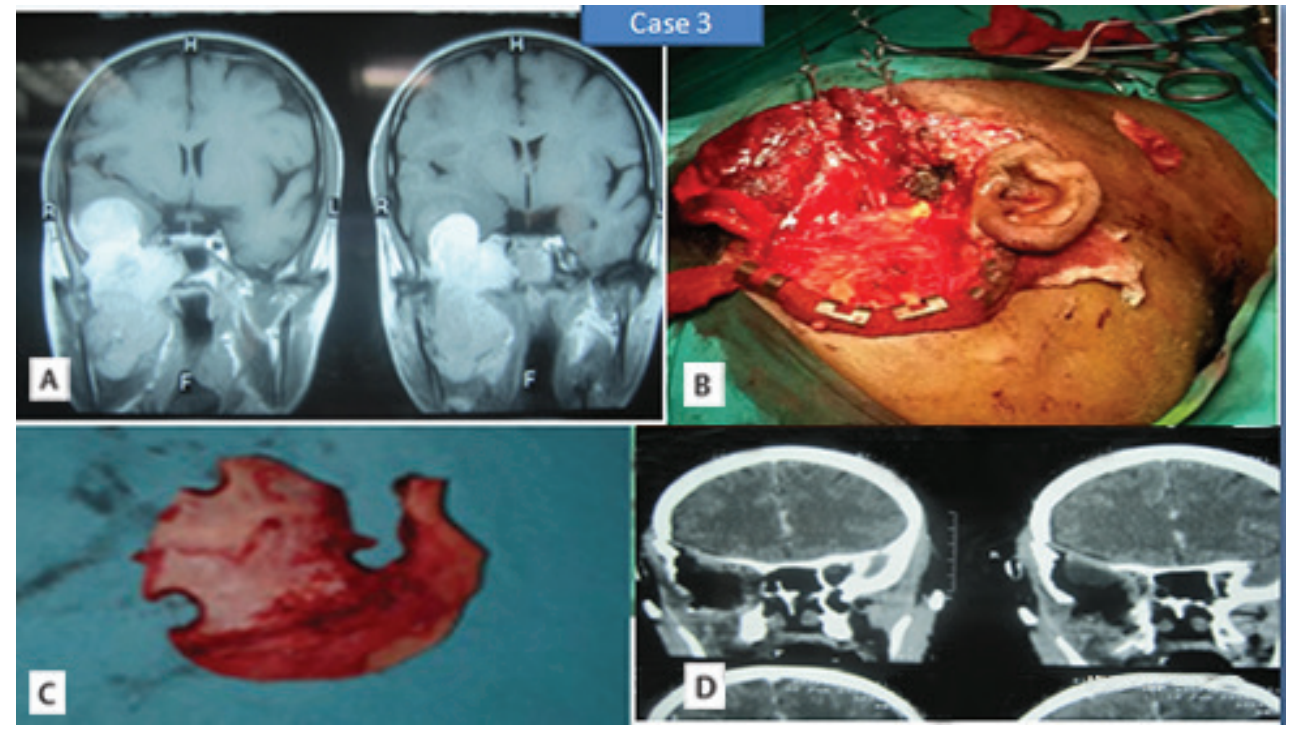

Fig. 2 Case 3. (A) Preoperative coronal T2 MRI showing chondrosarcoma with intracranial extradural lesion involving ITF and sphenoid. (B) Intraoperative image showing flap with orbitozygomatic osteotomies. (C) Specimen of orbitozygomatic osteotomy. (D) Postoperative coronal CT scan showing complete removal of tumor. CT, computed tomography; ITF, infratemporal fossa; MRI, magnetic resonance imaging.

for the resection of tumors arising in the ITF with intracranial extradural extension and tumors arising in the ITF and nearby structures and extending into the ITF. It does not allow safe resection of any portion of the tympanic bone. ${ }^{6}$

In our patients, the surgical approach began with a question mark incision (coronal incision with extension over preauricular region), which provided good exposure and was associated with good cosmetic outcome. Various other approaches such as translocation approach are also available, but due to cosmetic reasons, standard question mark incision was chosen ( - Fig. 4 , case 5). ${ }^{13}$ Craniofacial osteotomies were required in more than $90 \%$ of patients in both the groups to obtain adequate exposure of the tumor and a safe and complete resection. Our study favors the findings of another study in which cadaveric dissections were done and showed that surgical exposure of the ITF is superior when orbitozygomatic osteotomies are used..$^{14} \mathrm{~A}$ pterional craniotomy was required in all malignant cases. No vascularized flaps were used for reconstruction in all patients. The incision design was decided by the extension of the tumor. Orbitozygomatic osteotomies were used in patients whose tumors had medial and intracranial extensions. These associations confirmed that the surgery could be manipulated 

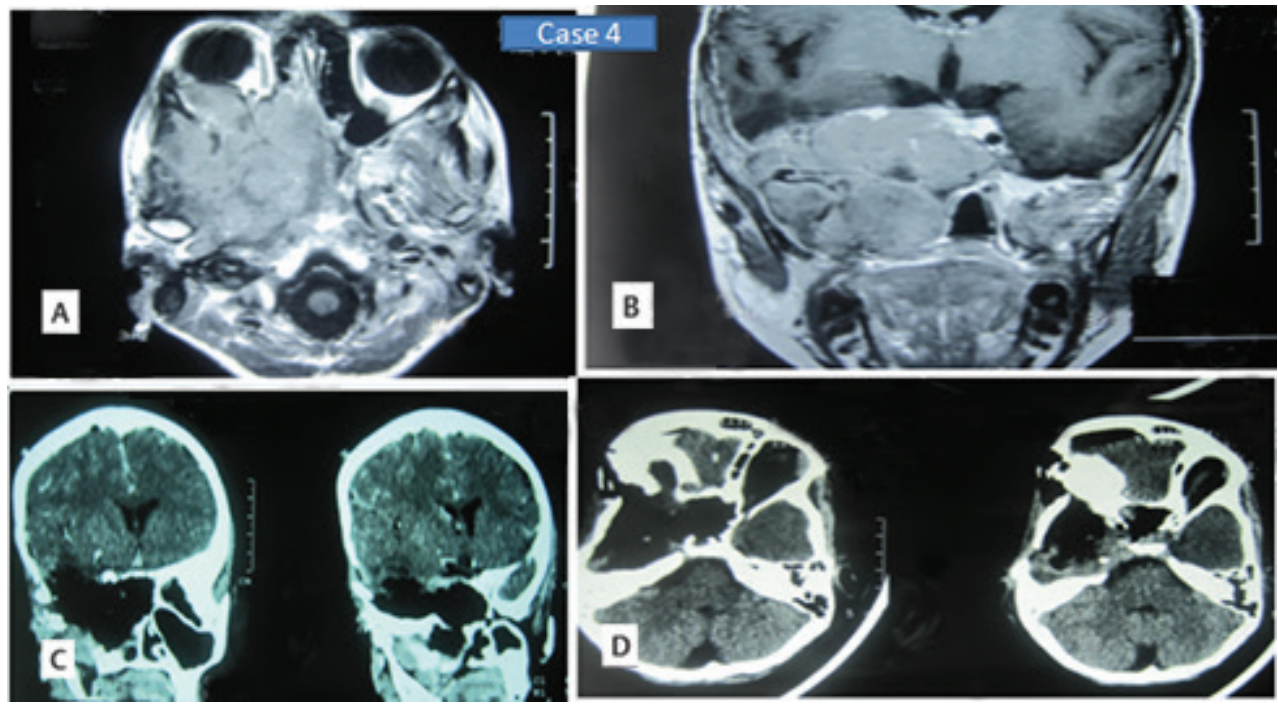

Fig. 3 Case 4. (A) Preoperative axial and T1 MRI images showing clear cell meningioma involving ITF, rt orbit, sphenoid with intracranial extradural extension. (B) Preoperative axial and T1 MRI images showing clear cell meningioma involving ITF, rt orbit, sphenoid with intracranial extradural extension. (C) Postoperative coronal CT scan showing complete removal of tumor. (D) Postoperative coronal CT scan showing complete removal of tumor. CT, computed tomography; ITF, infratemporal fossa; MRI, magnetic resonance imaging.
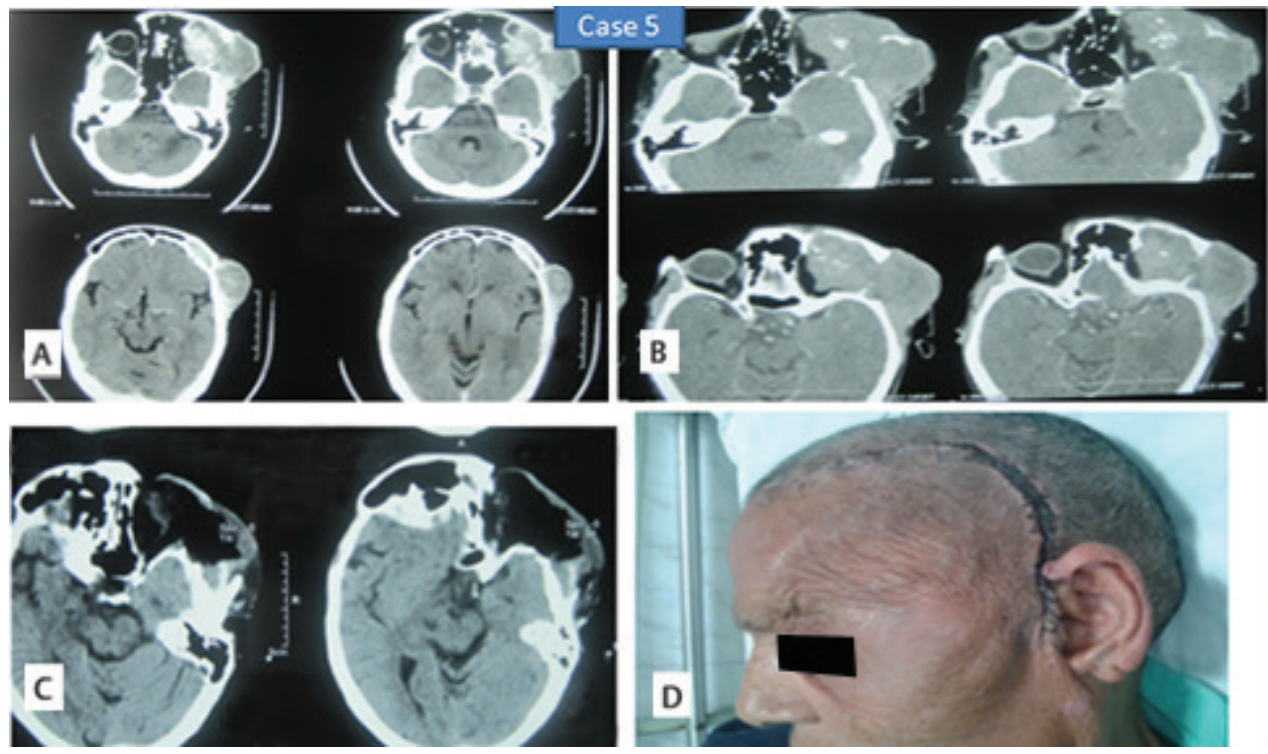

Fig. 4 Case 5. (A) Preoperative axial section of CT scan showing pleomorphic adenoma of minor salivary gland involving ITF with orbital extension and erosion of zygomatic bone. (B) Preoperative axial section of CT scan showing pleomorphic adenoma of minor salivary gland involving ITF with orbital extension and erosion of zygomatic bone. (C) Postoperative axial section CT scan showing complete removal of tumor. (D) Patient image showing postoperative scar of question mark incision. CT, computed tomography; ITF, infratemporal fossa.

as per the nature and extensions of a tumor. The differences between the two groups could be explained by the need for aggressive and wider tissue removal for malignant tumors, whereas benign tumors could be removed piecemeal without compromising outcomes. Surgical treatment provided adequate local control. Moreover, in both the groups, approximately three-fourths of the cases had no surgical complications. In the malignant group (i.e., intracranial extension, invasion of the soft tissues of the orbit), complications were significantly associated with need for a craniotomy, that is, the degree of morbidity was higher with more advanced surgery. In the malignant group, disease-free survival was improved by the use of postoperative radiotherapy.
Our study supports evidence-based assumption that the PTZA can be modified as per the nature and extent of a tumor. Incisions could be designed to provide adequate exposure of a tumor in all directions while facilitating cosmetic and functional reconstruction. Osteotomies were needed to enhance the surgical exposure in tumors with medial extensions; design of the craniotomy reflects the extent of superior or intracranial extensions. Other surgical procedures may be required to access medial extensions. Attempts should be made for complete tumor removal, but unnecessary procedures should be avoided to minimize morbidity rates. Use of adjunctive radiotherapy, chemotherapy, or both should be considered to improve the outcome of patients with malignant tumors. 


\section{Conclusion}

In our study, all benign and malignant tumors of the ITF are of major degree (involving more than one structure). The PTZA to the ITF is versatile and can be used to achieve complete resection of a variety of tumors restricted to the ITF with intracranial extradural extension. Incision used in preauricular transzygomatic approach is cosmetically sound than other available incisions for access to the ITF. This approach is better than endoscopic approach as it has wider access to the lateral ITF which is difficult to access through endoscopic approach. This approach can be tailored as per the nature of disease and its extensions. A detailed study with a larger sample size is further needed to establish the usefulness of this approach for ITF lesions.

\section{Conflict of Interest}

None.

\section{References}

1 Tiwari R, Quak J, Egeler S, et al. Tumors of the infratemporal fossa. Skull Base Surg 2000;10(1):1-9

2 Conley JJ. The surgical approach to the pterygoid area. Ann Surg 1956;144(1):39-43

3 Barbosa JF. Surgery of extensive cancer of paranasal sinuses. Presentation of a new technique. Arch Otolaryngol 1961;73:129-138
4 Sekhar LN, Schramm VLJr, Jones NF. Subtemporal-preauricular infratemporal fossa approach to large lateral and posterior cranial base neoplasms. J Neurosurg 1987;67(4):488-499

5 Ohue S, Fukushima T, Kumon Y, Ohnishi T, Friedman AH. Preauricular transzygomatic anterior infratemporal fossa approach for tumors in or around infratemporal fossa lesions. Neurosurg Rev 2012;35(4):583-592, discussion 592

6 Ruckenstein MJ, Denys D. Lateral skull-base surgery-a review of recent advances in surgical approaches. J Otolaryngol 1998;27(1):46-54

7 Youssef A, Carrau RL, Tantawy A, et al. Endoscopic versus open approach to the infratemporal fossa: a cadaver study. J Neurol Surg B Skull Base 2015;76(5):358-364

8 Conley JJ. Tumors of the infratemporal fossa. Arch Otolaryngol 1964;79:498-504

9 Bejjani GK, Sullivan B, Salas-Lopez E, et al. Surgical anatomy of the infratemporal fossa: the styloid diaphragm revisited. Neurosurgery 1998;43(4):842-852, discussion 852-853

10 Branovan DI, Schaefer SD. Lateral craniofacial approaches to the skull base and infratemporal fossa. Otolaryngol Clin North Am 2001;34(6):1175-1195

11 Schramm VL. Infratemporal fossa surgery. In: Sekhar LN, Schramm VL, eds. Tumors of the Cranial Base. Mount Kisco, New York (NY): Futura Publishing; 1987:235-251

12 Wetmore SJ, Suen JY, Snyderman NL. Preauricular approach to infratemporal fossa. Head Neck Surg 1986;9(2):93-103

13 Janecka IP, Sen CN, Sekhar LN, Nuss DW. Facial translocation for cranial base surgery. Keio J Med 1991;40(4):215-220

14 Honeybul S, Neil-Dwyer G, Lees PD, Evans BT, Lang DA. The orbitozygomatic infratemporal fossa approach: a quantitative anatomical study. Acta Neurochir (Wien) 1996;138(3): 255-264 